\title{
Computational analysis of microRNA-mediated interactions in SARS-CoV-2 infection
}

\author{
Müşerref Duygu Saçar Demirci ${ }^{\text {Corresp., } 1}$, Aysun Adan ${ }^{2}$ \\ 1 Bioinformatics, Abdullah Gul University, Kayseri, Turkey \\ 2 Molecular Biology and Genetics, Abdullah Gul University, Kayseri, Turkey \\ Corresponding Author: Müşerref Duygu Saçar Demirci \\ Email address: duygu.sacar@agu.edu.tr
}

MicroRNAs (miRNAs) are post-transcriptional regulators of gene expression found in more than 200 diverse organisms. Although it is still not fully established if RNA viruses could generate miRNAs, there are examples of miRNA like sequences from RNA viruses with regulatory functions. In the case of Severe acute respiratory syndrome coronavirus 2 (SARS-CoV-2), there are several mechanisms that would make miRNAs impact the virus, like interfering with viral replication, translation and even modulating the host expression. In this study, we performed a machine learning based miRNA prediction analysis for the SARS-CoV-2 genome to identify miRNA-like hairpins and searched for potential miRNA based interactions between the viral miRNAs and human genes and human miRNAs and viral genes. Overall, 950 hairpin structured sequences were extracted from the virus genome and based on the prediction results, 29 of them could be precursor miRNAs. Targeting analysis showed that 30 viral mature miRNA-like sequences could target 1367 different human genes. PANTHER gene function analysis results indicated that viral derived miRNA candidates could target various human genes involved in crucial cellular processes including transcription, metabolism, defense system and several signaling pathways such as Wnt and EGFR signalings. Protein class-based grouping of targeted human genes showed that host transcription might be one of the main targets of the virus since 96 genes involved in transcriptional processes were potential targets of predicted viral miRNAs. For instance, basal transcription machinery elements including several components of human mediator complex (MED1, MED9, MED12L, MED19), basal transcription factors such as TAF4, TAF5, TAF7L and site-specific transcription factors such as STAT1 were found to be targeted. In addition, many known human miRNAs appeared to be able to target viral genes involved in viral life cycle such as $S, M, N$, E proteins and ORF1ab, ORF3a, ORF8, ORF7a and ORF10. Considering the fact that miRNA-based therapies have been paid attention, based on the findings of this study, comprehending mode of actions of miRNAs and their possible roles during SARS-CoV-2 infections could 
create new opportunities for the development and improvement of new therapeutics. 
1 Computational analysis of microRNA-mediated

2 interactions in SARS-CoV-2 infection

3

4

5

6

7

Müşerref Duygu Saçar Demirci ${ }^{1}$, Aysun Adan ${ }^{2}$

${ }^{1}$ Department of Bioinformatics, Abdullah Gül University, Kayseri, Turkey

${ }^{2}$ Department of Molecular Biology and Genetics, Abdullah Gül University, Kayseri, Turkey

Corresponding Author:

Müşerref Duygu Saçar Demirci ${ }^{1}$

Erkilet Blv., Kayseri, 38080, Turkey

Email address: duygu.sacar@agu.edu.tr

\section{Abstract}

MicroRNAs (miRNAs) are post-transcriptional regulators of gene expression found in more than 200 diverse organisms. Although it is still not fully established if RNA viruses could generate miRNAs, there are examples of miRNA like sequences from RNA viruses with regulatory functions. In the case of Severe acute respiratory syndrome coronavirus 2 (SARS-CoV-2), there are several mechanisms that would make miRNAs impact the virus, like interfering with viral replication, translation and even modulating the host expression. In this study, we performed a machine learning based miRNA prediction analysis for the SARS-CoV-2 genome to identify miRNA-like hairpins and searched for potential miRNA - based interactions between the viral miRNAs and human genes and human miRNAs and viral genes. Overall, 950 hairpin structured sequences were extracted from the virus genome and based on the prediction results, 29 of them could be precursor miRNAs. Targeting analysis showed that 30 viral mature miRNA-like sequences could target 1367 different human genes. PANTHER gene function analysis results indicated that viral derived miRNA candidates could target various human genes involved in crucial cellular processes including transcription, metabolism, defense system and several signaling pathways such as Wnt and EGFR signalings. Protein class-based grouping of targeted human genes showed that host transcription might be one of the main targets of the virus since 96 genes involved in transcriptional processes were potential targets of predicted viral miRNAs. For instance, basal transcription machinery elements including several components of human mediator complex (MED1, MED9, MED12L, MED19), basal transcription factors such as TAF4, TAF5, TAF7L and site-specific transcription factors such as STAT1 were found to be targeted. In addition, many known human miRNAs appeared to be able to target viral genes involved in viral life cycle such as S, M, N, E proteins and ORF1ab, ORF3a, ORF8, ORF7a and ORF10. Considering the fact that miRNA-based therapies have been paid attention, based on the 
40 findings of this study, comprehending mode of actions of miRNAs and their possible roles

41 during SARS-CoV-2 infections could create new opportunities for the development and

42 improvement of new therapeutics.

43

44 Introduction

45 Coronoviruses (CoVs) are pathogens with serious health effects including enteric, respiratory, 46 hepatic and central nervous diseases on human and animals. Zoonotic CoVs, Severe Acute 47 Respiratory Syndrome-Coronavirus (SARS-CoV) and Middle East Respiratory Syndrome 48 coronavirus (MERS-CoV), have been identified the sources of outbreaks in 2002/2003 and 2012, 49 respectively with high mortality rates due to severe respiratory syndrome (de Wilde et al., 2018; 50 Chang, Yan \& Wang, 2020). Besides zoonotic CoVs, there are four types of human CoVs have 51 been identified known as HCoV-OC43, HCoV-2293, HCoV-NL63 and HCoV-HKU1 (de Wilde 52 et al., 2018). Unknown pneumonia have been detected in Wuhan, China and spread globally since December 2019. The World Health Organization (WHO) named this new coronavirus as disease termed Coronavirus Disease 2019 (COVID-19) and it is the seventh identified CoV with animal origin infecting human (Chang, Yan \& Wang, 2020).

SARS-CoV-2, positive-single stranded RNA ( + ssRNA) virus with exceptionally large genome with 5 'cap structure and 3'polyA tail, belongs to $\beta \mathrm{CoV}$ with $45-90 \%$ genetic similarity to SARS$\mathrm{CoV}$ based on sequence analysis and might share similar viral genomic and transcriptomic complexity (Deng \& Peng, 2020; Chen, Liu \& Guo, 2020). SARS-CoV-2 encodes non-structural proteins while others code for structural proteins required for viral replication and pathogenesis. Structural proteins include spike (S) glycoprotein, matrix (M) protein, small envelope (E) protein, and nucleocapsid $(\mathrm{N})$ protein with various roles for virus entrance and spread (Cheng \& Shan, 2020).

Currently, it has been also revealed that SARS-COV-2 has a very high homology with bat CoVs, which indicated how it is transmitted to human without knowing intermediate carriers (Zhou et al., 2020). S protein of SARS-CoV-2 has a strong interaction with human angiotensin-converting enzyme 2 (ACE2) expressed on alveolar epithelial cells which shows the way of virus infection in human (Xu et al., 2020).

MicroRNAs (miRNAs) are small, noncoding RNAs that play role in regulation of the gene expression in various organisms ranging from viruses to higher eukaryotes. It has been estimated that miRNAs might influence around $60 \%$ of mammalian genes and their main effect is on regulatory pathways including cancer, apoptosis, metabolism and development (Li \& Zou, 2019). 
79

80

81

82

83

84

85

86

87

88

89

90

91

92

93

94

95

96

97

98

99

100

101

102

103

104

105

106

107

108

109

110

111

112

113

115

116

117

Although the current release of miRNAs, the standard miRNA depository, lists miRNAs of 271 organisms, only 34 of them are viruses (Griffiths-Jones et al., 2008). While, the first virusencoded miRNAs was discovered for the human Epstein-Barr virus (EBV) (Pfeffer et al., 2004), more than 320 viral miRNA precursors were reported so far. Although it has been shown that various DNA viruses express miRNAs, it is still debatable if RNA viruses could also encode. The major concerns regarding miRNAs of RNA viruses are based on (Saçar Demirci, Toprak \& Allmer, 2016):

- the fact that RNA viruses that replicate in cytoplasm, do not have access to nuclear miRNA machinery

- $\quad$ since RNA is the genetic material, miRNA production would interfere with viral replication

The involvement of both host miRNAs and viral miRNAs in viral infections have been discussed extensively although their exact mechanistic roles in disease pathogenesis are not fully understood. In general, host miRNAs are produced as a part of antiviral response at early stage of viral infections to cope with the infection by directly or indirectly targeting viral replication, transcription and translation. However, some viruses have the ability to manipulate this response to escape from the host defense system and induce their own replication by triggering degradation of host miRNAs or inhibiting their maturation (Bruscella et al., 2017). On the other hand, viral miRNAs are produced to regulate their own lytic or latency phase transitions and to regulate the expression of host mRNAs involved in antiviral responses or cell metabolism (Bruscella et al., 2017).

Currently, options for the prevention and treatment of CoVs are very limited due to the complexity. Therefore, detailed analysis of CoV-host interactions is quite important to understand viral pathogenesis and to determine the outcomes of infection. Although there are studies regarding to the viral replication and their interaction with host innate immune system, the role of miRNA-mediated RNA-silencing in SARS-CoV-2 infection has not been enlightened yet. In this study, SARS-CoV-2 genome was searched for miRNA-like sequences and potential host-virus interactions based on miRNA actions were analyzed.

\section{Materials \& Methods}

Data analysis, pre-miRNA prediction, mature miRNA detection workflows were generated by using the Konstanz Information Miner (KNIME) platform (Berthold et al., 2008)

\section{Data}

Genome data of the virus was obtained from NCBI:

Severe acute respiratory syndrome coronavirus 2 isolate Wuhan-Hu-1, complete genome GenBank: MN908947.3 
118 MiRNA prediction workflow izMiR (Saçar Demirci, Baumbach \& Allmer, 2017) and its related data were

119 taken from Mendeley Data: https://data.mendeley.com/datasets/mgh5r9wny7/1

120 Mature miRNA sequences of human were downloaded from miRBase Release 22.1 (Kozomara \&

121 Griffiths-Jones, 2011).

\section{Pre-miRNA prediction}

123 Genome sequence of SARS-CoV-2 were transcribed (T->U) and divided into $500 \mathrm{nt}$ long fragments with 250 overlaps. Then these fragments were folded into their secondary structures by using RNAfold (Hofacker, 2003) with default settings and hairpin structures were extracted, producing 950 hairpins in total.

127 A modified version of izMiR (SVM classifier is changed to Random Forest and latest miRBase version was used for learning) was applied to these hairpins with ranging lengths (from 7 to 176) (Figure 1). Firstly, 1917 human precursor miRNAs from miRBase were used as positive data and izMiR training workflow was applied with $70 \%$ learning $-30 \%$ testing ratios, 1000 times. Since izMiR method is a consensus approach, at the end of learning phase, 39,000 models were created for 13 feature groups and 3 classifiers (Decision Tree, Naive Bayes and Random Forest). By selecting models with the highest accuracy scores, 39 models were applied to 950 viral hairpins. In order to select candidate pre-miRNA like sequences for further analysis, average of each classifiers' prediction scores was calculated. Then, overall average prediction score was calculated for each hairpin and by using minimum 0.900 as a threshold value, 29 hairpins were used for further analysis. miRBase as positive data instead of human. None of the 950 viral hairpins had minimum 0.900 overall average prediction score from these models' predictions (Supplementary File - viral hairpins). Based on the mean value of averages of 3 classifiers' prediction scores (Decision Tree, Naive Bayes and Random Forest), 29 hairpins passed 0.900 threshold and used for further analysis.

\section{Mature miRNA prediction and targeting}

143 Selected hairpins were further processed into smaller sequences; maximum $23 \mathrm{nt}$ length with $6 \mathrm{nt}$ 144 overlaps. Then, these fragments were filtered based on minimum length of 15 and their location on the 145 hairpins (sequences not involving any loop nucleotides were included). Target search of these remaining 14630 candidate mature miRNAs were performed against human and SARS-CoV-2 genes by using psRNATarget tool with default settings (Dai \& Zhao, 2011). Moreover, human mature miRNAs' from

148 miRBase were applied for searching their targets in SARS-CoV-2 genes.

\section{Gene Ontology}

151 The targets of viral miRNAs in human genes were further analyzed for their Gene Ontology (GO). To 152 achieve this, PANTHER Classification System (http://www.pantherdb.org) was used (Mi, Muruganujan 153 \& Thomas, 2013).

\section{Results}




\section{Pre-miRNA like sequence prediction from SARS-CoV-2 genome}

158

159

160

161

162

163

164

165

166

167

168

169

170

171

172

173

174

175

176

177

178

179

180

181

182

183

184

185

186

187

188

189

190

191

192

193

194

195

196

Searching SARS-CoV-2 genome for sequences forming hairpin structures resulted in 950 hairpins with varying lengths (Supplementary Files - viral hairpins). In order to use machine learning based miRNA prediction approach of izMiR workflows, hundreds of features were calculated for all of the pre-miRNA candidate sequences. Among those, minimum free energy (mfe) values required for the folding of secondary structures of hairpin sequences and hairpin sequence lengths of known human and virus miRNAs from miRBase and predicted hairpins of SARS-CoV-2 were compared (Figure 1). Based on the box-plots shown in Figure 1, most of the extracted viral hairpins seemed to be smaller than human miRNA precursors. Known viral and human pre-miRNAs share similarities both in length and mfe ranges. This could be due to the fact that viruses would need to use at least some members of host miRNA biogenesis pathway elements, therefore, viral miRNAs should be similar to host miRNAs to a certain degree. Therefore, a classification scheme trained with known human miRNAs was applied on SARSCoV-2 hairpins. Only 29 hairpins out of 950 passed the 0.900 prediction score threshold (Figure 1 - SARS-CoV-2*) and used for further analysis. From these hairpins, 30 mature miRNA candidates were extracted and their possible targets for human and SARS-CoV-2 genes were investigated.

The same classification approach was used to build models based on known viral hairpins too. However, these models' predictions on SARS-CoV-2 hairpins did not provide any candidates with average prediction scores equal or above 0.900 (Supplementary File - viral hairpins). This could be due to limited number of positive miRNA samples (320 hairpins for viruses) used for learning and/or quality of the datasets which is one of the most important elements of a classification analysis (Saçar Demirci and Allmer, 2017).

\section{Sequence similarity}

SARS-CoV-2 miRNA candidates were further analyzed to test if they were similar to any of the known mature miRNAs from 271 organism listed in miRBase. To achieve this, a basic similarity search was performed based on the Levenshtein distance calculations in KNIME. However, there was no significant similarity between hairpin or mature sequences.

\section{Human gene targets of viral miRNA-like RNAs}

Predicted mature miRNA-like sequences of SARS-CoV-2 were used to find their targets in SARS-CoV-2 and human genes, mature miRNAs of human were also applied on SARS-CoV-2 genes (Table 1, Supplementary Files - virus to human targets, virus to virus targets). Although miRNA based self-regulation of viral gene expression is a hypothetical case, SARS-CoV-2 ORF 1 ab polyprotein gene might be the only one that could be a target of viral miRNAs. In total 1367 human genes seemed to be targeted by viral miRNAs.

Peer) reviewing PDF | (2020:04:47579:1:0:NEW 9 May 2020) 
197 It has been shown that viruses could lower host transcription to benefit viral gene expression and

198

199

200

201

202

203

204

205

206

207

208

209

210

211

212

213

214

215

216

217

218

219

220

221

222

223

224

225

226

227

228

229

230

231

232

233

234

235

236

also reduce the effect of the immune system (Lyles, 2000). "Host shutoff" is a phenomenon observed when several human viruses including SARS, lead to a global decrease in the host protein production (Harwig, Landick \& Berkhout, 2017). Since host transcription process appear to be an important target for viruses, Table 1 lists some of the predicted targets of SARS-CoV-2 miRNAs in human genes that have roles in transcription. The full list of miRNA - target predictions are available in Supplementary Files.

\section{SARS-CoV-2 gene targets of human miRNAs}

Considering the potential of miRNAs as biomarkers and therapeutic agents, it is essential to check if any of the known human miRNAs could target viral genes. Among 2654 mature entries of Homo sapiens in miRBase Release 22.1, 479 of them could target SARS-CoV-2 genes (Supplementary Files - human to virus). While Envelope and ORF6 genes were targeted by single miRNAs, ORF1ab appeared to be the target of 369 different human mature miRNAs (Table 2). As expected, number of targeting events appeared to be correlated with the gene length.

\section{GO of targeted human genes}

Lastly, in order to understand the main mechanisms that would be affected by the influence of viral miRNA-like sequences on human genes, PANTHER Classification System was applied to targeted human genes. Based on the results presented in Figure $2-3$ and Supplementary Files, a wide range of human genes with various molecular functions and pathways could be targeted. According to the protein classes of targeted human genes, metabolite interconversion enzyme (110 genes) and gene-specific transcriptional regulator (96 genes) were the most likely candidates as targets of viral miRNA-like sequences. For the defense/immunity protein class, six genes (IGSF1, IGSF3, VSTM4, CD48, CD84, PI15) appeared to be targeted.

Pathway based GO analysis revealed that overall 101 pathways might be influenced by viral miRNA like sequences. Among them, Gonadotropin-releasing hormone receptor pathway was the most targeted with 25 genes, followed by various signaling pathways including Wnt signaling pathway (21 genes), EGF receptor signaling pathway (17 genes), CCKR signaling map (16 genes), FGF signaling pathway (16 genes) and PDGF signaling pathway (15 genes) (Figure $3)$.

By comparing the predicted human gene targets of SARS-CoV-2 miRNA candidates with recent protein - protein interactions (PPI) data between human and virus (Gordon et al., 2020), 28 common proteins were identified (Supplementary File - PPI). Thus, these human proteins might not only be associated with viral proteins but also be targets of viral miRNA-like sequences. 


\section{Discussion}

238 The potential roles of miRNA-mediated RNA interference in infection biology has been defined

239

240

241

242

243

244

245

246

247

248

249

250

251

252

253

254

255

256

257

258

259

260

261

262

263

264

265

266

267

268

269

270

271

272

273

274

275

276 as an essential regulatory molecular pathway. The involvement of miRNAs in host-pathogen interactions during infection might include the targeting of viral genes by host-cellular miRNAs as well as evolution of DNA and RNA virus-based gene silencing mechanisms to overcome host antiviral response and to maintain viral infection and disease (Ghosh, Mallick \& Chakrabarti, 2009; Piedade \& Azevedo-Pereira, 2016). In addition, viruses might use host cellular miRNAs for their own advantage. Therefore, molecular elucidation of the roles of miRNAs in host-virus interaction might provide a deeper understanding for viral pathogenesis and the development of an effective antiviral therapy as shown in several viruses including Herpesvirus, Enterovirus and Hepatitis C (Piedade \& Azevedo-Pereira, 2016; Engelmann et al., 2018; Khatun \& Ray, 2019). Although the detailed knowledge about viral miRNAs have been obtained from DNA viruses, it is still controversial for RNA viruses that whether they produce their own miRNAs or not (Mishra et al., 2019). However, there are several reports showing the presence of non-canonical (due to the lack of classical stem-loop structure in miRNAs), small miRNA-like small RNAs produced during viral infections as shown in H5N1 Influenza (Li et al., 2018), Ebola virus (Liang et al., 2014) and HIV-1 (Klase et al., 2009). Although they play crucial roles in several viral infections, miRNAs have not been studied in the pathogenesis of SARS-CoV-2 infection. In this study, we elucidated the presence of miRNAs in SARS-CoV-2 infection by predicting possible host genes targeted by viral miRNA-like small RNAs and viral genes targeted by cellular miRNAs, which might provide potential ways to understand the underlying mechanisms of SARS-CoV-2 infection.

We investigated SARS-CoV-2 encoded genes targeted by host-cellular miRNAs as shown in Table 2, which are mainly responsible for viral biogenesis, entrance, replication and infection. Except envelope (E) protein and ORF6, all viral genes (S, M, N, ORF1ab, ORF3a, ORF8, ORF7a and ORF10) are targeted by multiple human miRNAs. For instance, hsa-miR-203b-3p targeted ORF1 ab and ORF3a with roles in viral replication was already shown to suppress influenza A virus replication (Zhang et al., 2018). Even though hsa-miR-148a-3p targeted ORF8 to prevent interspecies transmission and also replication, it was found to target $\mathrm{S}, \mathrm{E}, \mathrm{M}$ and ORF1a protein in closely related SARS-CoV (Mallick, Ghosh \& Chakrabarti, 2009). hsa-let-7c$5 p$ targeted ORF1ab in SARS-CoV-2 while it was found to be involved in H1N1 influenza A suppression by targeting its M1 protein (Ma et al., 2012). In another study, ORF6 of SARS-CoV suppressed type I interferon signaling by blocking the nuclear transport of STAT1 in the presence of interferon $\beta$ (Huang et al., 2017), therefore, hsa-miR-190a-5p might target ORF6 to overcome immune system escape in SARS-CoV-2. The presence of such miRNAs could be considered as a host's innate antiviral defense mechanism. On the other hand, virus could use these miRNAs to suppress their own replication to escape from immune system at the beginning of infection and transmission for a stronger infection. For instance, miR-146a-5p was upregulated in hepatitis $C$ virus-infected liver cells of patients and in infected human hepatocytes, which promoted virus particle assembly (Bandiera et al., 2016). Moreover, ss RNA

Peer) reviewing PDF | (2020:04:47579:1:0:NEW 9 May 2020) 
277 viruses could evolve very rapidly to change their gene sequences matching with these host 278 miRNAs, therefore, they increase their host specificity. Once the virus establishes a successful 279 transmission inside the host, they would mutate their genes very rapidly to escape from host 280 miRNAs, which results from their RNA polymerases without proofreading activity (Ye, 281 Montalto-Morrison \& Masters, 2004; Trobaugh \& Klimstra, 2017).

282 Virus-derived miRNAs might function by targeting host and virus-encoded transcripts to 283 regulate host-pathogen interaction. The roles of viral miRNAs in pathogenesis include alteration 284 of host defense mechanisms and regulation of crucial biological processes including cell 285 survival, proliferation, modulation of viral life-cycle phase (Raza Naqvi et al., 2020). Although 286 287 encoding miRNAs seems quite problematic for RNA viruses due to the nature of miRNA biogenesis pathway, it is possible to circumvent these problems through different ways as seen in HIV-1 (Klase et al., 2009). Therefore, we analyzed possible human genes targeted by predicted miRNA like small RNAs (Supplementary File) and focused on the genes involved in transcription (Table 1). Based on the panther analysis, regulators of eukaryotic transcription would be the most important targets of 18 SARS-CoV-2 derived mature miRNA like candidates out of 29 hairpins in total. These transcriptional regulators are involved in both basal transcription machinery including several components of human mediator complex (MED1, MED9, MED12L, MED19) and basal transcription factors such as TAF4, TAF5 and TAF7L. Viruses might downregulate host gene expression in order to increase their gene expression either co-transcriptionally in the nucleus or post-transcriptionally in the nucleus or cytoplasm (Herbert \& Nag, 2016). Therefore, targeting basal transcription machinery such as components (TAFs) of TFIID complex by SARS-CoV-2 could prevent RNA polymerase II to assemble on promoters of host genes at the initiation step. Viral factors have been shown to block transcription initiation by inhibiting TFIID or more specifically TAF4 in herpesvirus (Yang \& Chang, 2013). Another interesting target gene by SARS-CoV-2 miRNA was different subunits of CCR4-NOT transcription complex including CNOT4, CNOT10 and CNOT6L, which are deadenylases involved in mRNA decay (Abernathy \& Glaunsinger, 2015). Therefore, suppression of these genes by viral miRNAs could impede mRNA turnover in the host and provide opportunities for viral mRNA to escape from degradation. Additionally, site specific trans-acting factors such as MAFG, STAT1, STAT5B and SOX11 would be targeted by viral miRNAs. STAT family transcription factors are activated by cytokine-induced stimuli and generally involved in an interferon response. In Kaposi's sarcoma-associated herpesvirus (KSHV), viral miRNAs were found to inhibit STAT3 and STAT5, resulting in deregulated interferon response and transition into lytic viral replication (Ramalingam \& Ziegelbauer, 2017). In a recent study, interactions between 26 SARS-COV-2 proteins and human proteins were investigated by using affinity-purification mass spectrometry (Gordon et al., 2020) and the results were found to be in accordance with some results presented in this study. When we compared our predicted SARS-COV2 miRNA like RNA targets in human with these 332 human proteins, we found out that there are 28 protein targets in common (Supplementary File - PPI) and these targets are involved in biological processes including protein trafficking, translation, transcription and ubiquitination regulation similar to our Panther analysis results. 
322

323

324

325

326

327

328

329

330

331

332

333

334

335

336

337

338

339

340

341

342

343

344

345

346

347

348

349

350

351

352

353

354

355

356

357

358

359

360

361

362

As a conclusion, viral diseases have been paid attention as a global health problem due to the lack of proper treatment strategies and rapid evolution of viruses. In recent years, studies have focused on identifying miRNAs as targets for the treatment of viral diseases and there are potential miRNA therapeutics under investigation which aim to overexpress or replace, inhibit or repress miRNAs in the cells or tissues Based on the results shown in Table 2, it can be concluded that increases in the level of host miRNAs targeting virulent genes such as $\mathrm{S}, \mathrm{M}, \mathrm{N}, \mathrm{E}$ and ORF1ab would block viral entry and replication. Moreover, decreasing the levels of host miRNAs would make SARS-CoV-2 more replicative and visible for the host immune system. However, alterations in host miRNA levels would interfere with specific cellular processes which are crucial for the host biology. In our study, we have also identified possible miRNA like small RNAs from SARS-CoV-2 genome which target important human genes. Therefore, antagomirs targeting viral miRNAs could be also designed even though there are only a few studies for DNA viruses (Herbert \& Nag, 2016). Antagomirs have been the most studied miRNA inhibiting approach among other therapeutics including small molecule inhibitors and miRNA sponges and there are promising clinical phase studies evaluating the therapeutic potential of antagomirs targeting host miRNAs such as miR-122 in hepatitis C (van der Ree et al., 2017). On the other hand, studies have also continued to overcome some obstacles including difficult entrance into the target cells, in vivo instability and lower binding affinities to their targets in order to increase the effectiveness of antagomirs (Simonson \& Das, 2015). In addition to inhibition of miRNAs in the target cells, some miRNAs with lower expression should be overexpressed or replaced by using miRNA mimics. Most miRNA mimics as with antagomirs need to be modified to prevent their degradation and increase their uptake by the cells (JL et al., 2017). However, all these therapeutic possibilities need further mechanistical evaluations to understand how they regulate virus-host interaction. Therefore, further in vitro, ex vivo and in vivo studies will be required to validate candidate miRNAs for SARS-CoV-2 infection.

\section{Acknowledgements}

\section{References}

Abernathy E, Glaunsinger B. 2015. Emerging roles for RNA degradation in viral replication and antiviral defense. Virology 479-480:600-8. DOI: 10.1016/j.virol.2015.02.007.

Bandiera S, Pernot S, El Saghire H, Durand SC, Thumann C, Crouchet E, Ye T, Fofana I, Oudot MA, Barths J, Schuster C, Pessaux P, Heim MH, Baumert TF, Zeisel MB. 2016. Hepatitis C Virus-Induced Upregulation of MicroRNA miR-146a-5p in Hepatocytes Promotes Viral Infection and Deregulates Metabolic Pathways Associated with Liver Disease Pathogenesis. Journal of virology 90:6387-6400. DOI: 10.1128/JVI.00619-16.

Berthold MR, Cebron N, Dill F, Gabriel TR, Kötter T, Meinl T, Ohl P, Sieb C, Thiel K, Wiswedel B. 2008. KNIME: The Konstanz Information Miner. In: SIGKDD Explorations. 319-326. DOI: 10.1007/978-3-540-78246-9_38.

Bruscella P, Bottini S, Baudesson C, Pawlotsky J-M, Feray C, Trabucchi M. 2017. Viruses and

Peer] reviewing PDF | (2020:04:47579:1:0:NEW 9 May 2020) 
363

364

365

366

367

368

369

370

371

372

373

374

375

376

377

378

379

380

381

382

383

384

385

386

387

388

389

390

391

392

393

394

395

396

397

398

399

400

401

402

403

404

405

406

407

408

miRNAs: More Friends than Foes. Frontiers in microbiology 8:824. DOI: 10.3389/fmicb.2017.00824.

Chang L, Yan Y, Wang L. 2020. Coronavirus Disease 2019: Coronaviruses and Blood Safety. Transfusion Medicine Reviews. DOI: 10.1016/J.TMRV.2020.02.003.

Chen Y, Liu Q, Guo D. 2020. Emerging coronaviruses: Genome structure, replication, and pathogenesis. Journal of medical virology 92:418-423. DOI: 10.1002/jmv.25681.

Cheng ZJ, Shan J. 2020. 2019 Novel coronavirus: where we are and what we know. Infection:19. DOI: 10.1007/s15010-020-01401-y.

Dai X, Zhao PX. 2011. PsRNATarget: A plant small RNA target analysis server. Nucleic Acids Research 39:W155-9. DOI: 10.1093/nar/gkr319.

Demirci MDS, Allmer J. 2017. Delineating the impact of machine learning elements in premicroRNA detection. PeerJ 2017. DOI: 10.7717/peerj.3131.

Deng S-Q, Peng H-J. 2020. Characteristics of and Public Health Responses to the Coronavirus Disease 2019 Outbreak in China. Journal of clinical medicine 9. DOI:

$10.3390 /$ jcm 9020575 .

Engelmann I, Alidjinou EK, Bertin A, Sane F, Hober D. 2018. miRNAs in enterovirus infection. Critical reviews in microbiology 44:701-714. DOI: 10.1080/1040841X.2018.1499608.

Ghosh Z, Mallick B, Chakrabarti J. 2009. Cellular versus viral microRNAs in host-virus interaction. Nucleic acids research 37:1035-48. DOI: 10.1093/nar/gkn1004.

Gordon DE, Jang GM, Bouhaddou M, Xu J, Obernier K, White KM, O’Meara MJ, Rezelj V V., Guo JZ, Swaney DL, Tummino TA, Huettenhain R, Kaake RM, Richards AL, Tutuncuoglu B, Foussard H, Batra J, Haas K, Modak M, Kim M, Haas P, Polacco BJ, Braberg H, Fabius JM, Eckhardt M, Soucheray M, Bennett MJ, Cakir M, McGregor MJ, Li Q, Meyer B, Roesch F, Vallet T, Mac Kain A, Miorin L, Moreno E, Naing ZZC, Zhou Y, Peng S, Shi Y, Zhang Z, Shen W, Kirby IT, Melnyk JE, Chorba JS, Lou K, Dai SA, Barrio-Hernandez I, Memon D, Hernandez-Armenta C, Lyu J, Mathy CJP, Perica T, Pilla KB, Ganesan SJ, Saltzberg DJ, Rakesh R, Liu X, Rosenthal SB, Calviello L, Venkataramanan S, Liboy-Lugo J, Lin Y, Huang X-P, Liu Y, Wankowicz SA, Bohn M, Safari M, Ugur FS, Koh C, Savar NS, Tran QD, Shengjuler D, Fletcher SJ, O’Neal MC, Cai Y, Chang JCJ, Broadhurst DJ, Klippsten S, Sharp PP, Wenzell NA, Kuzuoglu D, Wang H-Y, Trenker R, Young JM, Cavero DA, Hiatt J, Roth TL, Rathore U, Subramanian A, Noack J, Hubert M, Stroud RM, Frankel AD, Rosenberg OS, Verba KA, Agard DA, Ott M, Emerman M, Jura N, von Zastrow M, Verdin E, Ashworth A, Schwartz O, d'Enfert C, Mukherjee S, Jacobson M, Malik HS, Fujimori DG, Ideker T, Craik CS, Floor SN, Fraser JS, Gross JD, Sali A, Roth BL, Ruggero D, Taunton J, Kortemme T, Beltrao P, Vignuzzi M, García-Sastre A, Shokat KM, Shoichet BK, Krogan NJ. 2020. A SARS-CoV-2 protein interaction map reveals targets for drug repurposing. Nature:1-13. DOI: 10.1038/s41586-020-2286-9.

Griffiths-Jones S, Saini HK, van Dongen S, Enright AJ. 2008. miRBase: tools for microRNA genomics. Nucleic acids research 36:D154-8. DOI: 10.1093/nar/gkm952.

Harwig A, Landick R, Berkhout B. 2017. The Battle of RNA Synthesis: Virus versus Host. Viruses 9. DOI: 10.3390/V9100309.

Herbert KM, Nag A. 2016. A Tale of Two RNAs during Viral Infection: How Viruses Antagonize mRNAs and Small Non-Coding RNAs in The Host Cell. Viruses 8. DOI: 10.3390/v8060154.

Hofacker IL. 2003. Vienna RNA secondary structure server. Nucleic Acids Research 31:3429_ 3431. DOI: $10.1093 /$ nar/gkg599. 
409

410

411

412

413

414

415

416

417

418

419

420

421

422

423

424

425

426

427

428

429

430

431

432

433

434

435

436

437

438

439

440

441

442

443

444

445

446

447

448

449

450

451

452

453

454

Huang S-H, Lee T-Y, Lin Y-J, Wan L, Lai C-H, Lin C-W. 2017. Phage display technique identifies the interaction of severe acute respiratory syndrome coronavirus open reading frame 6 protein with nuclear pore complex interacting protein NPIPB3 in modulating Type I interferon antagonism. Journal of microbiology, immunology, and infection $=$ Wei mian yu gan ran za zhi 50:277-285. DOI: 10.1016/j.jmii.2015.07.002.

JL M, S R, A A, J R, UF P, J S, BM D, AH B. 2017. Broad-Spectrum Inhibition of Respiratory Virus Infection by MicroRNA Mimics Targeting p38 MAPK Signaling. Molecular therapy. Nucleic acids 7. DOI: 10.1016/J.OMTN.2017.03.008.

Khatun M, Ray RB. 2019. Mechanisms Underlying Hepatitis C Virus-Associated Hepatic Fibrosis. Cells 8. DOI: 10.3390/cells8101249.

Klase Z, Winograd R, Davis J, Carpio L, Hildreth R, Heydarian M, Fu S, McCaffrey T, Meiri E, Ayash-Rashkovsky M, Gilad S, Bentwich Z, Kashanchi F. 2009. HIV-1 TAR miRNA protects against apoptosis by altering cellular gene expression. Retrovirology 6:18. DOI: 10.1186/1742-4690-6-18.

Kozomara A, Griffiths-Jones S. 2011. miRBase: integrating microRNA annotation and deepsequencing data. Nucleic acids research 39:D152-7. DOI: 10.1093/nar/gkq1027.

Li X, Fu Z, Liang H, Wang Y, Qi X, Ding M, Sun X, Zhou Z, Huang Y, Gu H, Li L, Chen X, Li D, Zhao Q, Liu F, Wang H, Wang J, Zen K, Zhang C-Y. 2018. H5N1 influenza virusspecific miRNA-like small RNA increases cytokine production and mouse mortality via targeting poly(rC)-binding protein 2. Cell research 28:157-171. DOI: 10.1038/cr.2018.3.

Li X, Zou X. 2019. An overview of RNA virus-encoded microRNAs. ExRNA 1:37. DOI: 10.1186/s41544-019-0037-6.

Liang H, Zhou Z, Zhang S, Zen K, Chen X, Zhang C. 2014. Identification of Ebola virus microRNAs and their putative pathological function. Science China. Life sciences 57:97381. DOI: $10.1007 / \mathrm{s} 11427-014-4759-2$.

Lyles DS. 2000. Cytopathogenesis and Inhibition of Host Gene Expression by RNA Viruses. Microbiology and Molecular Biology Reviews 64:709-724. DOI: 10.1128/MMBR.64.4.709-724.2000.

Ma Y-J, Yang J, Fan X-L, Zhao H-B, Hu W, Li Z-P, Yu G-C, Ding X-R, Wang J-Z, Bo X-C, Zheng X-F, Zhou Z, Wang S-Q. 2012. Cellular microRNA let-7c inhibits M1 protein expression of the H1N1 influenza A virus in infected human lung epithelial cells. Journal of cellular and molecular medicine 16:2539-46. DOI: 10.1111/j.1582-4934.2012.01572.x.

Mallick B, Ghosh Z, Chakrabarti J. 2009. MicroRNome analysis unravels the molecular basis of SARS infection in bronchoalveolar stem cells. PloS one 4:e7837. DOI: 10.1371/journal.pone.0007837.

Mi H, Muruganujan A, Thomas PD. 2013. PANTHER in 2013: modeling the evolution of gene function, and other gene attributes, in the context of phylogenetic trees. Nucleic acids research 41:D377-86. DOI: 10.1093/nar/gks1118.

Mishra R, Kumar A, Ingle H, Kumar H. 2019. The Interplay Between Viral-Derived miRNAs and Host Immunity During Infection. Frontiers in immunology 10:3079. DOI: 10.3389/fimmu.2019.03079.

Pfeffer S, Zavolan M, Grässer FA, Chien M, Russo JJ, Ju J, John B, Enright AJ, Marks D, Sander C, Tuschl T. 2004. Identification of virus-encoded microRNAs. Science (New York, N.Y.) 304:734-6. DOI: 10.1126/science.1096781.

Piedade D, Azevedo-Pereira JM. 2016. The Role of microRNAs in the Pathogenesis of Herpesvirus Infection. Viruses 8. DOI: 10.3390/v8060156.

Peer) reviewing PDF | (2020:04:47579:1:0:NEW 9 May 2020) 
455

456

457

458

459

460

461

462

463

464

465

466

467

468

469

470

471

472

473

474

475

476

477

478

479

480

481

482

483

484

485

486

487

488

489

490

491

492

493

494

495

496

497

498

Ramalingam D, Ziegelbauer JM. 2017. Viral microRNAs Target a Gene Network, Inhibit STAT Activation, and Suppress Interferon Responses. Scientific reports 7:40813. DOI: 10.1038/srep40813.

Raza Naqvi A, Ahmad I, Valverde A, Siddiqui H, Schaller S. 2020. Viral MicroRNAs: Interfering the Interferon Signaling. Current pharmaceutical design. DOI: 10.2174/1381612826666200109181238.

van der Ree MH, de Vree JM, Stelma F, Willemse S, van der Valk M, Rietdijk S, Molenkamp R, Schinkel J, van Nuenen AC, Beuers U, Hadi S, Harbers M, van der Veer E, Liu K, Grundy J, Patick AK, Pavlicek A, Blem J, Huang M, Grint P, Neben S, Gibson NW, Kootstra NA, Reesink HW. 2017. Safety, tolerability, and antiviral effect of RG-101 in patients with chronic hepatitis $\mathrm{C}$ : a phase $1 \mathrm{~B}$, double-blind, randomised controlled trial. Lancet (London, England) 389:709-717. DOI: 10.1016/S0140-6736(16)31715-9.

Saçar Demirci MD, Baumbach J, Allmer J. 2017. On the performance of pre-microRNA detection algorithms. Nature Communications 8:330. DOI: 10.1038/s41467-017-00403-z.

Saçar Demirci MD, Toprak M, Allmer J. 2016. A Machine Learning Approach for MicroRNA Precursor Prediction in Retro-transcribing Virus Genomes. Journal of integrative bioinformatics 13. DOI: 10.2390/biecoll-jib-2016-303.

Simonson B, Das S. 2015. MicroRNA Therapeutics: the Next Magic Bullet? Mini reviews in medicinal chemistry 15:467.

Trobaugh DW, Klimstra WB. 2017. MicroRNA Regulation of RNA Virus Replication and Pathogenesis. Trends in molecular medicine 23:80-93. DOI: 10.1016/j.molmed.2016.11.003.

de Wilde AH, Snijder EJ, Kikkert M, van Hemert MJ. 2018. Host Factors in Coronavirus Replication. Current topics in microbiology and immunology 419:1-42. DOI: $10.1007 / 82$ 2017_25.

Xu X, Chen P, Wang J, Feng J, Zhou H, Li X, Zhong W, Hao P. 2020. Evolution of the novel coronavirus from the ongoing Wuhan outbreak and modeling of its spike protein for risk of human transmission. Science China Life Sciences 63:457-460. DOI: 10.1007/s11427-0201637-5.

Yang Y-C, Chang L-K. 2013. Role of TAF4 in transcriptional activation by Rta of Epstein-Barr Virus. PloS one 8:e54075. DOI: 10.1371/journal.pone.0054075.

Ye R, Montalto-Morrison C, Masters PS. 2004. Genetic analysis of determinants for spike glycoprotein assembly into murine coronavirus virions: distinct roles for charge-rich and cysteine-rich regions of the endodomain. Journal of virology 78:9904-17. DOI: 10.1128/JVI.78.18.9904-9917.2004.

Zhang S, Li J, Li J, Yang Y, Kang X, Li Y, Wu X, Zhu Q, Zhou Y, Hu Y. 2018. Up-regulation of microRNA-203 in influenza A virus infection inhibits viral replication by targeting. Scientific Reports 8. DOI: 10.1038/s41598-018-25073-9.

Zhou P, Yang X-L, Wang X-G, Hu B, Zhang L, Zhang W, Si H-R, Zhu Y, Li B, Huang C-L, Chen H-D, Chen J, Luo Y, Guo H, Jiang R-D, Liu M-Q, Chen Y, Shen X-R, Wang X, Zheng X-S, Zhao K, Chen Q-J, Deng F, Liu L-L, Yan B, Zhan F-X, Wang Y-Y, Xiao G-F, Shi Z-L. 2020. A pneumonia outbreak associated with a new coronavirus of probable bat origin. Nature:1-4. DOI: 10.1038/s41586-020-2012-7. 


\section{Figure 1}

Box-plots for comparison of general features of human pre-miRNAs and virus premiRNAs from miRBase and SARS-CoV-2 hairpins.

(A) Hairpin lengths. (B) Minimum free energy scores obtained from RNAfold (Hofacker 2003). SARS-CoV-2 refers to all 950 hairpins extracted from the virus genome while SARS-CoV-2* indicates 29 selected hairpins. 


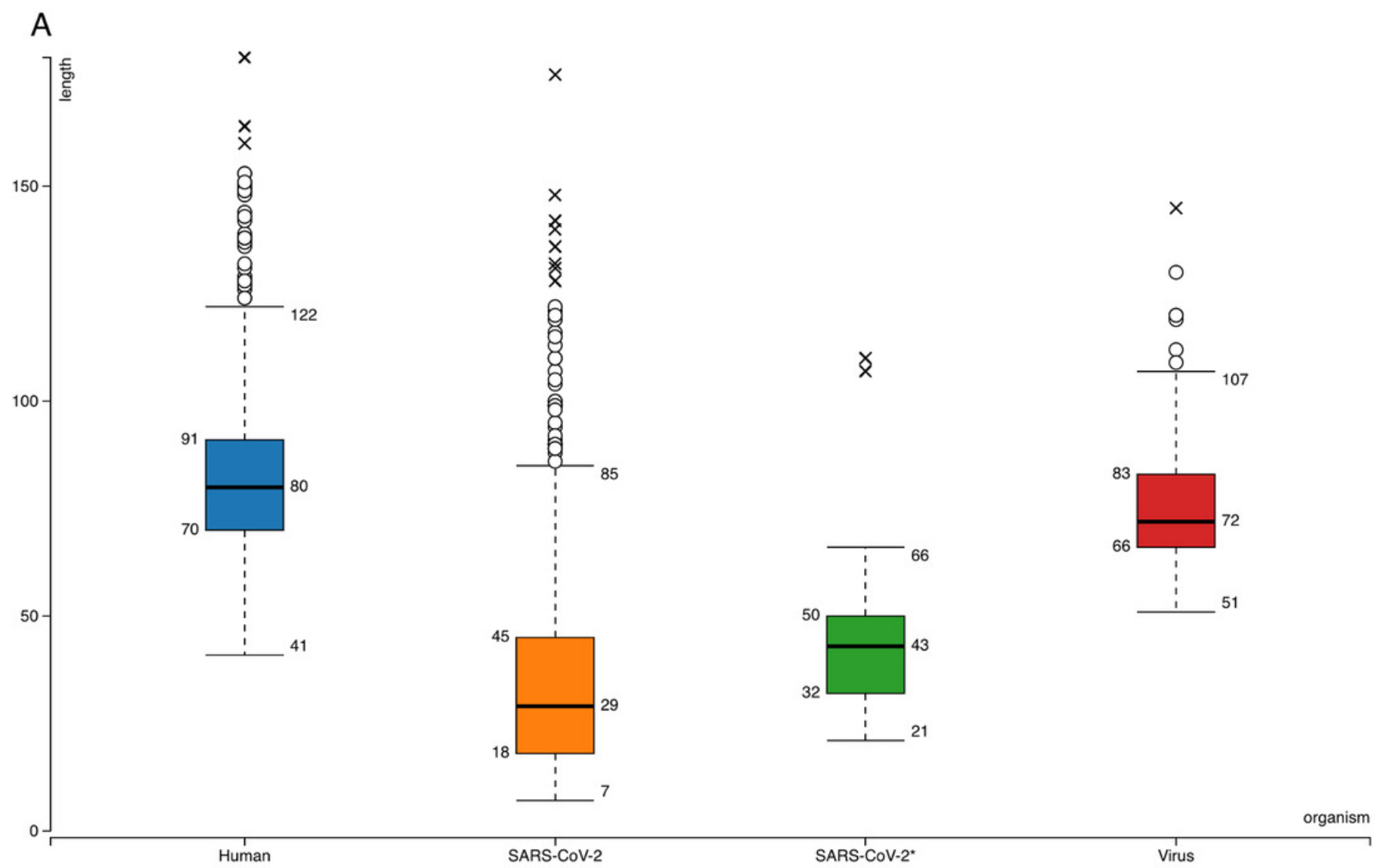

\section{B}
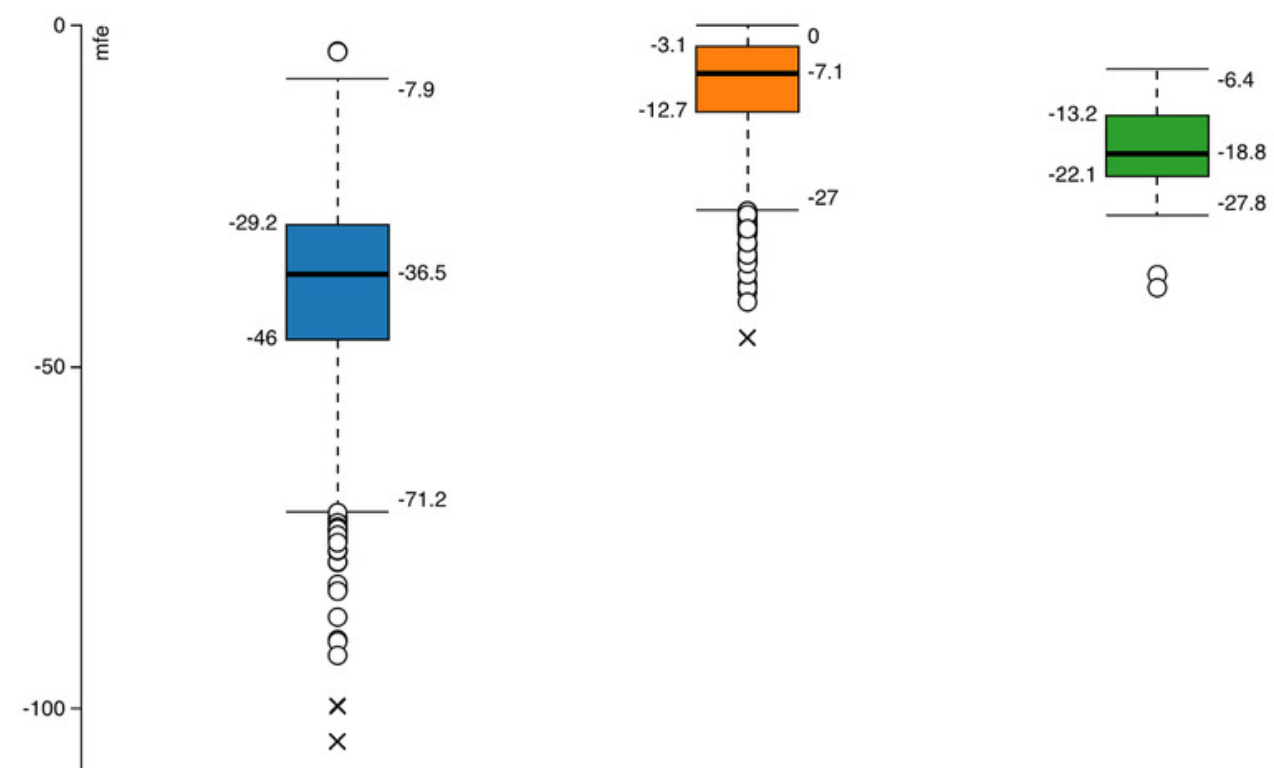

8

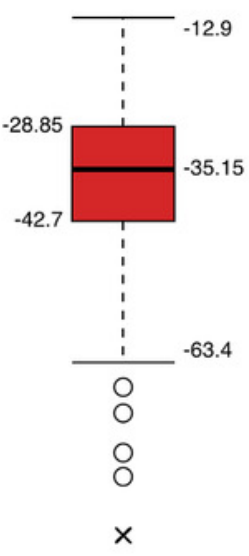

$\times$

$\times$

$-150\rfloor$

$\times$

Human

SARS-CoV-2

SARS-CoV-2*

organism 


\section{Figure 2}

Bar-chart for the protein classes of human genes that could be targeted by viral miRNAs.

Protein classes of genes were obtained from Panther. X-axis shows the number of genes with respected classes.

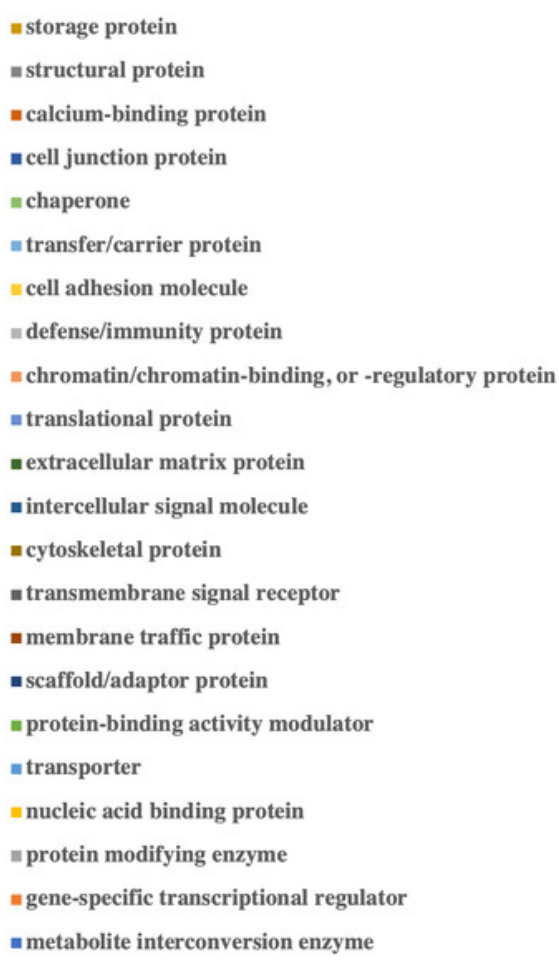

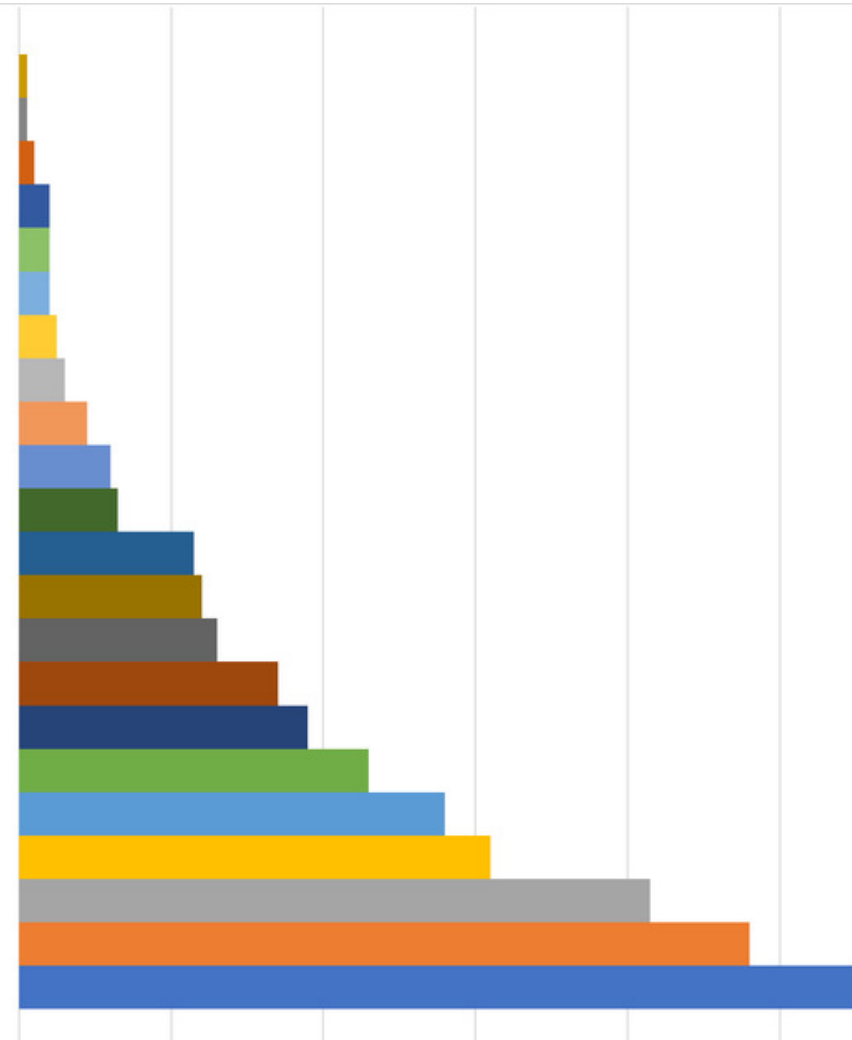




\section{Figure 3}

Bar-chart for the pathways of human genes that could be targeted by viral miRNAs.

Graph is limited to the pathways that have at least 10 genes. Pathways of genes were obtained from Panther. Y-axis shows the number of genes with respected pathways. Chart and legend are sorted from maximum to minimum (left to right and top to bottom, respectively).

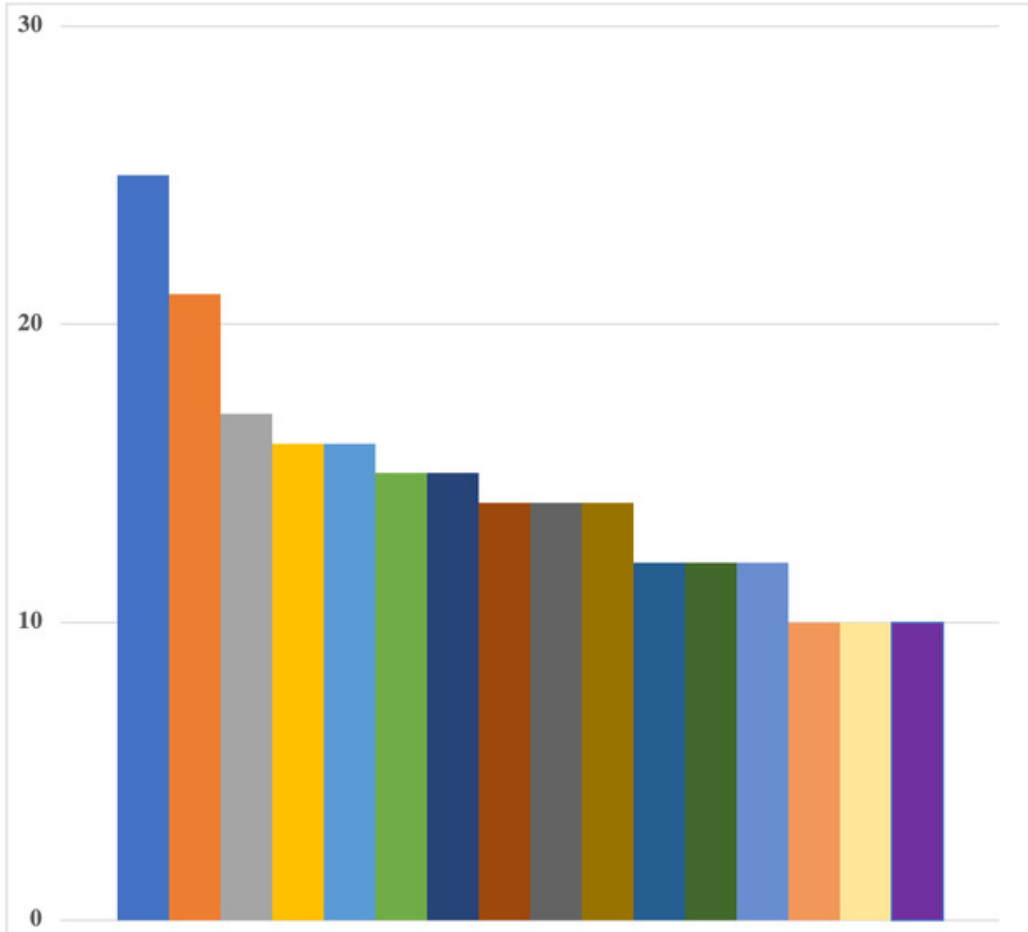

= Gonadotropin-releasing hormone receptor pathway
= Wnt signaling pathway
= EGF receptor signaling pathway
= CCKR signaling map
= FGF signaling pathway
= PDGF signaling pathway
- Huntington disease
- Angiogenesis
- Integrin signalling pathway
= Heterotrimeric G-protein signaling pathway-Gi alpha and Gs alpha
mediated pathway
- TGF-beta signaling pathway
- Inflammation mediated by chemokine and cytokine signaling pathway
= Heterotrimeric G-protein signaling pathway-Gq alpha and Go alpha
mediated pathway
= Apoptosis signaling pathway
- Alzheimer disease-amyloid secretase pathway
- p5athway feedback loops 2




\section{Table $\mathbf{1}$ (on next page)}

Transcription related human gene targets of viral miRNAs.

MiRNA column indicates the sequences of mature viral miRNAs; Target gene \# column shows the total number of different genes involved in transcription and targeted by the corresponding viral miRNAs. 


\begin{tabular}{|c|c|c|}
\hline miRNA & $\begin{array}{l}\text { Target } \\
\text { gene \# }\end{array}$ & Target Gene Names \\
\hline GUUUUCAUCAACUUUUAAC & 11 & $\begin{array}{l}\text { CNOT4 (CCR4-NOT transcription complex } \\
\text { subunit 4), MED9 (Mediator of RNA } \\
\text { polymerase II transcription subunit 9), } \\
\text { GTF2H5 (General transcription factor IIH } \\
\text { subunit 5), MED1 (Mediator of RNA } \\
\text { polymerase II transcription subunit 1), } \\
\text { STAT5B (Signal transducer and activator of } \\
\text { transcription 5B), TAF4 (Transcription } \\
\text { initiation factor TFIID subunit 4), EBF1 } \\
\text { (Transcription factor COE1), CNOT10 } \\
\text { (CCR4-NOT transcription complex subunit } \\
\text { 10), MAFG (Transcription factor MafG), } \\
\text { BACH1 (Transcription regulator protein } \\
\text { BACH1), MED12L (Mediator of RNA } \\
\text { polymerase II transcription subunit 12-like } \\
\text { protein) }\end{array}$ \\
\hline $\begin{array}{l}\text { ACGUUGCAAUUUAGGUGGUG } \\
\mathrm{C}\end{array}$ & 4 & $\begin{array}{l}\text { CNOT4 (CCR4-NOT transcription complex } \\
\text { subunit 4), TFDP2 (Transcription factor Dp- } \\
\text { 2), TCF4 (Transcription factor 4), MITF } \\
\text { (Microphthalmia-associated transcription } \\
\text { factor) }\end{array}$ \\
\hline $\begin{array}{l}\text { AGCUAGCUCUUGGAGGUUCC } \\
\text { GUG }\end{array}$ & 3 & $\begin{array}{l}\text { LST1 (Leukocyte-specific transcript } 1 \\
\text { protein), EBF4 (Transcription factor COE4), } \\
\text { TFEC (Transcription factor EC) }\end{array}$ \\
\hline $\begin{array}{l}\text { AUAAGCUCAUGGGACACUUC } \\
\text { GCA }\end{array}$ & 3 & $\begin{array}{l}\text { HES2 (Transcription factor HES-2), TAF5 } \\
\text { (Transcription initiation factor TFIID subunit } \\
\text { 5), TFEC (Transcription factor EC) }\end{array}$ \\
\hline $\begin{array}{l}\text { UAUGUACCACUAAAGUCUGC } \\
\text { UAC }\end{array}$ & 3 & $\begin{array}{l}\text { SOX11 (Transcription factor SOX-11), } \\
\text { MED19 (Mediator of RNA polymerase II } \\
\text { transcription subunit 19), NFYB (Nuclear } \\
\text { transcription factor Y subunit beta) }\end{array}$ \\
\hline $\begin{array}{l}\text { UUGAUAAAGUACUUAAUGAG } \\
\text { AAG }\end{array}$ & 2 & $\begin{array}{l}\text { TEAD1 (Transcriptional enhancer factor } \\
\text { TEF-1), DMRT1 (Doublesex- and mab-3- } \\
\text { related transcription factor 1) }\end{array}$ \\
\hline $\begin{array}{l}\text { AAGUACUUAAUGAGAAGUGC } \\
\text { UCU }\end{array}$ & 2 & $\begin{array}{l}\text { TFDP2 (Transcription factor Dp-2), TCF4 } \\
\text { (Transcription factor } 4 \text { ) }\end{array}$ \\
\hline AUUUAGGUGGUGCUGUCUGU & 2 & $\begin{array}{l}\text { CTCFL (Transcriptional repressor CTCFL), } \\
\text { CNOT6L (CCR4-NOT transcription complex } \\
\text { subunit 6-like) }\end{array}$ \\
\hline $\begin{array}{l}\text { CAUGUAUUCUGUUAUGCUUA } \\
\text { CUA }\end{array}$ & 2 & $\begin{array}{l}\text { TRPS1 (Zinc finger transcription factor } \\
\text { Trps1), CREBZF (CREB/ATF bZIP } \\
\text { transcription factor) }\end{array}$ \\
\hline $\begin{array}{l}\text { CUGCCUAUACAGUUGAACUC } \\
\text { GGU }\end{array}$ & 1 & $\begin{array}{l}\text { BRF1 (Transcription factor IIIB } 90 \mathrm{kDa} \\
\text { subunit) }\end{array}$ \\
\hline
\end{tabular}




\begin{tabular}{|l|l|l|}
\hline $\begin{array}{l}\text { GUACCACUAAAGUCUGCUAC } \\
\text { GUG }\end{array}$ & 1 & $\begin{array}{l}\text { NFYB (Nuclear transcription factor Y subunit } \\
\text { beta) }\end{array}$ \\
\hline $\begin{array}{l}\text { AACAAAAGCUAGCUCUUGGA } \\
\text { GGU }\end{array}$ & 1 & $\begin{array}{l}\text { SUPT5H (Transcription elongation factor } \\
\text { SPT5) }\end{array}$ \\
\hline $\begin{array}{l}\text { UCCGUGGCUAUAAAGAUAAC } \\
\text { AGA }\end{array}$ & 1 & $\begin{array}{l}\text { MYT1L (Myelin transcription factor 1-like } \\
\text { protein) }\end{array}$ \\
\hline $\begin{array}{l}\text { UCAUGGGACACUUCGCAUGG } \\
\text { UGG }\end{array}$ & 1 & $\begin{array}{l}\text { PHTF2 (Putative homeodomain transcription } \\
\text { factor 2) }\end{array}$ \\
\hline $\begin{array}{l}\text { CCUGUGUUGUGGCAGAUGCU } \\
\text { GUC }\end{array}$ & 1 & $\begin{array}{l}\text { TAF7L (Transcription initiation factor TFIID } \\
\text { subunit 7-like) }\end{array}$ \\
\hline $\begin{array}{l}\text { UUGUGGCAGAUGCUGUCAUA } \\
\text { AAA }\end{array}$ & 1 & $\begin{array}{l}\text { POU2F1 (POU domain, class 2, transcription } \\
\text { factor 1) }\end{array}$ \\
\hline $\begin{array}{l}\text { AUAGAUUAUGUACCACUAAA } \\
\text { GUC }\end{array}$ & 1 & $\begin{array}{l}\text { STAT1 (Signal transducer and activator of } \\
\text { transcription 1-alpha/beta) }\end{array}$ \\
\hline $\begin{array}{l}\text { CAACCUAUACUGUUACUAGA } \\
\text { UCA }\end{array}$ & 1 & SWT1 (Transcriptional protein SWT1) \\
\hline
\end{tabular}

1 


\section{Table 2 (on next page)}

Predicted viral mRNA targets by human miRNAs: bold miRNAs are the common ones targeting more than one indicated viral proteins.

The functions of SARS-CoV-2 proteins are not fully characterized, however, its coding genes might share functional similarity with SARS-CoV as shown in column "Functions of Target Genes". Gene size indicates the size of genes in terms of number of nucleotides, hsa miRNAs shows the number of different human miRNAs that could target indicated viral genes. 


\begin{tabular}{|c|c|c|}
\hline Target Genes & Human miRNA & Functions of Target Genes \\
\hline $\begin{array}{c}\text { S (Spike) } \\
\text { protein } \\
\text { gene size: } 3822 \\
\text { hsa miRNAs: } 67\end{array}$ & $\begin{array}{c}\text { hsa-miR-447b, hsa-miR-2052, hsa-miR- } \\
\text { 3127-5p, hsa-miR-34b-5p, hsa-miR- } \\
\text { 374a-3p, hsa-miR-6729-5p, hsa-miR- } \\
\text { 3927-3p, hsa-miR-410-5p, hsa-miR- } \\
\text { 432-5p, hsa-miR-4693-3p, hsa-miR- } \\
\text { 548ag, hsa-miR-6128, hsa-miR-676-3p, } \\
\text { hsa-miR-6809-5p, hsa-miR-6893-5p }\end{array}$ & $\begin{array}{l}\text { Viral attachment for the host } \\
\text { cell entry by interacting with } \\
\text { ACE2 (Gallagher and } \\
\text { Buchmeier 2001; Xu et al. } \\
\text { 2020) }\end{array}$ \\
\hline $\begin{array}{l}\text { E (Envelope) } \\
\text { protein } \\
\text { gene size: } 228 \\
\text { hsa miRNAs: } 1\end{array}$ & hsa-miR-3672 & $\begin{array}{l}\text { Viral envelope formation and } \\
\text { acting as viroporin to form } \\
\text { hydrophilic pores on host } \\
\text { membranes (Wilson et al. } \\
\text { 2004; Castaño-Rodriguez et al. } \\
\text { 2018) }\end{array}$ \\
\hline $\begin{array}{c}\text { M (Membrane) } \\
\text { protein } \\
\text { gene size: } 669 \\
\text { hsa miRNAs: } 10\end{array}$ & $\begin{array}{c}\text { hsa-miR-325, hsa-miR-34a-5p, hsa-miR- } \\
\text { 6820-5p, hsa-miR-1252-5p, hsa-miR- } \\
\text { 1262, hsa-miR-2355-3p, hsa-miR-382-5p, } \\
\text { hsa-miR-215-3p, hsa-miR-5047, hsa- } \\
\text { miR-6779-5p }\end{array}$ & $\begin{array}{l}\text { Defining the shape of viral } \\
\text { envelope, the central organiser } \\
\text { of CoV assembly } \\
\text { (Masters 2006; Neuman et al. } \\
\text { 2011) }\end{array}$ \\
\hline $\begin{array}{c}\mathbf{N} \\
\begin{array}{c}\text { (Nucleocapsid) } \\
\text { protein }\end{array} \\
\text { gene size: } 1260 \\
\text { hsa miRNAs: } 21\end{array}$ & $\begin{array}{c}\text { hsa-miR-8066, hsa-miR-1911-3p, hsa- } \\
\text { miR-4259, hsa-miR-6838-3p, hsa-miR- } \\
\text { 208a-5p, hsa-miR-4445-5p, hsa-miR- } \\
\text { 451b, hsa-miR-6082, hsa-miR-8086, hsa- } \\
\text { miR-1282, hsa-miR-1301-3p, hsa-miR- } \\
\text { 154-5p, hsa-miR-1910-3p, hsa-miR- } \\
\text { 3155a, hsa-miR-342-5p, hsa-miR-593- } \\
\text { 3p, hsa-miR-639, hsa-miR-6729-5p, hsa- } \\
\text { miR-6741-5p, hsa-miR-6876-5p, hsa- } \\
\text { miR-6882-3p }\end{array}$ & $\begin{array}{l}\text { Only protein primarily binding } \\
\text { to the CoV RNA genome to } \\
\text { form nucleocapsid (Masters } \\
\text { 2006) }\end{array}$ \\
\hline $\begin{array}{c}\text { ORF1ab } \\
\text { gene size: } 21291 \\
\text { hsa miRNAs: } \\
369\end{array}$ & $\begin{array}{l}\text { hsa-miR-153-5p, hsa-let-7c-5p, hsa- } \\
\text { miR-1910-3p, hsa-miR-342-5p, hsa- } \\
\text { miR-4436b-3p, hsa-miR-5047, hsa- } \\
\text { miR-203b-3p, hsa-miR-2052, hsa-miR- } \\
\text { 3127-5p, hsa-miR-3190-3p, miR-34b- } \\
\text { 5p, hsa-miR-3672, hsa-miR-374a-3p, } \\
\text { hsa-miR-3927-3p, hsa-miR-410-5p, } \\
\text { hsa-miR-432-5p, hsa-miR-4436a, hsa- } \\
\text { miR-4482-3p, hsa-miR-4693-3p, hsa- } \\
\text { miR-5011-3p, hsa-miR-548ag, hsa- } \\
\text { miR-593-3p, hsa-miR-6128, hsa-miR- }\end{array}$ & $\begin{array}{l}\text { Encoding 5'- viral replicase } \\
\text { (Graham et al. 2008) }\end{array}$ \\
\hline
\end{tabular}




\begin{tabular}{|c|c|c|}
\hline & $\begin{array}{l}\text { 676-3p, hsa-miR-6809-5p, hsa-miR- } \\
\text { 6820-5p, hsa-miR-6866-5p, hsa-miR- } \\
\text { 6893-5p }\end{array}$ & \\
\hline $\begin{array}{c}\text { ORF3a } \\
\text { gene size: } 828 \\
\text { hsa miRNAs: } 16\end{array}$ & $\begin{array}{l}\text { hsa-miR-549a-3p, hsa-miR-1246, hsa- } \\
\text { miR-7704, hsa-miR-203b-3p, hsa-miR- } \\
\text { 342-5p, hsa-miR-4422, hsa-miR-4510, } \\
\text { hsa-miR-1229-5p, hsa-miR-190b-5p, hsa- } \\
\text { miR-203a-3p, hsa-miR-367-5p, hsa-miR- } \\
\text { 4436b-3p, hsa-miR-4482-3p, hsa-miR- } \\
\text { 541-3p, hsa-miR-6751-5p, hsa-miR- } \\
\text { 6891-5p, hsa-miR-4482-3p }\end{array}$ & $\begin{array}{l}\text { a sodium or calcium ion } \\
\text { channel protein, involved in } \\
\text { replication and pathogenesis } \\
\text { together with E and ORF8a } \\
\text { (Castaño-Rodriguez et al. } \\
\text { 2018) }\end{array}$ \\
\hline $\begin{array}{c}\text { ORF8 } \\
\text { gene size: } 366 \\
\text { hsa miRNAs: } 13\end{array}$ & $\begin{array}{c}\text { hsa-miR-12129, hsa-miR-5047, hsa-miR- } \\
\text { 148a-3p, hsa-miR-23b-5p, hsa-miR- } \\
\text { 5011-3p, hsa-miR-12119, hsa-miR-2392, } \\
\text { hsa-miR-3190-3p, hsa-miR-3529-5p, } \\
\text { hsa-miR-369-3p, hsa-miR-455-5p, hsa- } \\
\text { miR-4779, hsa-miR-648 }\end{array}$ & $\begin{array}{l}\text { Might be important for } \\
\text { interspecies transmission (Lau } \\
\text { et al. 2015; Castaño-Rodriguez } \\
\text { et al. 2018) in addition to its } \\
\text { roles in replication }\end{array}$ \\
\hline $\begin{array}{c}\text { ORF7a } \\
\text { gene size: } 366 \\
\text { hsa miRNAs: } 8\end{array}$ & $\begin{array}{l}\text { hsa-miR-4436a, hsa-miR-3135b, hsa- } \\
\text { miR-4436b-3p, hsa-miR-4774-5p, hsa- } \\
\text { miR-6731-5p, hsa-miR-6866-5p, hsa- } \\
\text { miR-1910-3p, hsa-miR-5590-3p }\end{array}$ & $\begin{array}{l}\text { accessory protein that is } \\
\text { composed of a type I } \\
\text { transmembrane protein, } \\
\text { induction of apoptosis in a } \\
\text { caspase-dependent pathway } \\
\text { (Tan et al. 2007; Schaecher et } \\
\text { al. 2007) }\end{array}$ \\
\hline $\begin{array}{c}\text { ORF10 } \\
\text { gene size: } 117 \\
\text { hsa miRNAs: } 4\end{array}$ & $\begin{array}{l}\text { hsa-miR-3682-5p, hsa-miR-411-5p, hsa- } \\
\text { miR-379-5p, hsa-miR-548v }\end{array}$ & $\begin{array}{l}\text { Might be involved in } \\
\text { transspecies transmission } \\
\text { (Paraskevis et al. 2020) }\end{array}$ \\
\hline $\begin{array}{c}\text { ORF6 } \\
\text { gene size: } 186 \\
\text { hsa miRNAs: } 1\end{array}$ & hsa-miR-190a-5p & $\begin{array}{l}\text { Blocking nuclear import of } \\
\text { STAT1 by binding to nuclear } \\
\text { imports (Frieman et al. 2007) }\end{array}$ \\
\hline
\end{tabular}

